\title{
Pemanfaatan Trichokompos Pada Budidaya Sayuran Organik Sebagai Kegiatan Entrepreneurship Himae
}

\author{
Jasminarni, Ardiyaningsih Puji Lestari, Evita, Trias Novita \\ Fakultas Pertanian Universitas Jambi \\ Email corresponding author : jasmi_narni@unja.ac.id
}

\begin{abstract}
ABSTRAK
Kegiatan ini bertujuan meningkatkan pengetahuan dan ketrampilan mitra melalui pendampingan, penyuluhan dan demontrasi tentang pemanfaatan trichokompos pada budidaya sayuran organik sebagai kegiatan Entrepreneurship HIMAE (Himpunan Mahasiswa Agroekoteknologi). Secara umum target luaran yang akan dicapai akan memberi dampak terhadap Masyarakat umumnya dan kelompok mitra khususnya, serta masyarakat disekitarnya. Dampak positif yang diharapkan tercapai melalui kegiatan ini dimana tim pengabdiaan akan melakukan pelatihan dan demontrasi kelompok HIMAE sebagai mitra dalam hal pemanfaatan trichokompos yang merupakan hasil produk pada kegiatan PPM tahun sebelumnya sebagai pupuk dan juga dapat berdampak terhadap lingkungan yang bersih dan sehat. Tim pengabdian juga akan memberikan cara cara untuk meningkatkan nilai jual produk sayuran organik dengan cara membuat kemasan. Diharapkan dari upaya tersebut produk sayuran organik yang dihasilkan dapat dijadikan sebagai kegiatan wirausaha yang bernilai ekonomi bagi HIMAE, sehingga dapat menjadi tambahan penghasilan bagi mitra. Luaran yang dihasikan adalah berupa produk sayuran organik. Pemanfaatan trichokompos pada budidaya sayuran merupakan salah satu upaya membantu mengatasi pencemaran lingkungan dan kerusakan lahan akibat penggunaan pupuk kimia. Hasil yang didapat dari kegiatan ini adalah meningkatnya pengetahuan mitra tentang pentingnya penggunaan pupuk organik pada budidaya sayuran organik yang dihasilkan. Sayuran organik yang dapat di kosumsi dan di jual sebagai kegiatan Entrepreneurship HIMAE
\end{abstract}

Kata Kunci: Sayuran organik, Trichokompos, Kemasan

\section{PENDAHULUAN}

Kampus merupakan salah satu lokasi yang digunakan sebagai sarana pembelajaran baik teori maupun praktek. Setiap kampus berlomba-lomba menjadi perguruan tinggi yang berkualitas dunia (world class university). Salah satu syarat kampus memperoleh predikat berkualitas dunia dengan cara turut berpartisipasi menyelesaikan permasalahan global, khususnya pengelolaan lingkungan. Pengelolaan sampah merupakan bagian dari pengelolaan lingkungan yang harus didukung karena berkaitan dengan green-campus. Terciptanya kampus yang bersih, sehat dan nyaman merupakan faktor utama yang mendorong kampus mendapat predikat green kampus.

Sampah-sampah yang pada mulanya tidak termanfaatan ini akhirnya sebagian telah dimanfaatkan oleh Himpunan Mahasiswa Agroekoteknologi (HIMAE) sebagai bahan baku pembuatan produk trichokompos yang menjadi produk PPM yang mereka hasilkan pada kegiatan PPM tahun lalu. Untuk keberlanjutan kegiatan ini maka pada kegiatan penerapan iptek tahun ini akan kita coba aplikasikan trichokompos ini ke budidaya tanaman sayuran yang akan menghasilkan sayuran organik.

Kelompok HIMAE merupakan Himpunan Mahasiswa Agroekoteknologi di Fakultas Pertanian Universitas Jambi, yang berdiri tanggal 4 februari 2010. Dimana salah satu tujuan 
dari HIMAE ini adalah meningkatkan ilmu pengetahuan, kemampuan, keahlian dan sikap tanggung jawab, mempunyai jiwa kewirausahaan yang di harapkan dapat di kembangkan lebih lanjut. Pemanfaatan trichokomos pada budidaya sayuran organik dengan memanfaatkan trichokompos hasil penerapan iptek kegiatan PPM HIMAE tahun lalu dapat dijadikan sebagai salah satu usaha ekonomi bagi HIMAE nantinya, karena mereka dapat memasarkan trichokompos dan sayuran organik tersebut untuk keperluan masyarakat lainnya.

Mereka akan melakukan pengemasan pada sayuran organik yang dihasilkan disamping masih tetap menyediakan trichokompos yang dihasilkan. Manfaat pemakaian trichokompos berbasis sampah organik kampus pada budidaya sayuran adalah :

1. Mampu melaksanakan pertanian yang murah dan ramah lingkungan.

2. Mengurangi pemakaian pupuk kimia sehingga dapat mengurangi pencemaran lingkungan .

3. Membantu pengaplikasian produk yang sudah dihasilkan pada kegiatan iptek sebelumnya.

4. Membantu dalam menghasilkan sayuran organik yang bebas bahan kimia sehingga baik bagi kesehatan.

5. Menghemat biaya budidaya dengan menghasilkan pupuk organik sendiri dari limbah yang ada disekitarnya.

6. Menyelamatkan lingkungan dari kerusakan dan pencemaran dari pupuk kimia yang digunakan.

7. HIMAE dapat membantu dalam memasarkan produk sayuran organik yang

dihasilkan sehingga dapat digunakan sebagai salah satu usaha ekonomi HIMAE. Dari hasil pantauan yang dilakukan tim di lokasi pengabdian di lapangan, maka dapat diidentifikasi permasalahan dan skala prioritas penanganan masalah sebagai berikut :

1. Meningkatkan kegiatan kelompok mahasiswa yang mengarah pada wirausaha di bidang pertanian.

2. Meningkatkan minat mahasiswa untuk melakukan kegiatan budidaya sayuran organik

3. Meningkatkan pengetahuan mitra tentang pengemasan produk sehingga mempunyai nilai ekonomi sehingga dapat dijadikan sebagai kegiatan wirausaha HIMAE.

Mitra HIMAE dapat menghasikan sayuran organik dari hasil produk budidayanya sebagai salah satu usaha ekonomi (wirausaha). Disamping itu mitra juga dapat mengaplikasikan hasil produk yang dihaslkan pada tahun sebelumnya yaitu trichokompos yang akan digunakan sebagai pupuk yang akan dapat menggantikan penggunaan pupuk kimia sebagai salah satu upaya mencegah pencemaran lingkungan dan kerusakan lahan.

Target luaran dari kegitan ini adalah meningkatkan pengetahuan tentang wirausaha di bidang pertanian Sayuran Organik, meningkatkan pengetahuan mitra tentang pemanfaatan pupuk organic dan pengemasan produk sayuran organik. Produk yang dihasilkan akan dipasarkan secara online dan langsung kepada konsumen. Tahap awal pemasaran akan dilakukan untuk lingkungan kampus.

\section{PELAKSANAAN DAN METODE}

Kegiatan ini dilaksanakan di Fakultas Pertanian Universitas Jambi, mitra yang mengikuti kegiatan ini adalah mahasiswa dari Himpunan Mahasiswa agroekoteknologi (HIMAE) mereka adalah dari kelompok wirausaha. Jumlah mitra yang terlibat aktif pada kegiatan ini adalah 6 orang.

Kegiatan ini dibagi menjadi 3 tahapan yaitu : Pengenalan program, kegiatan demontrasi dan pembinaan serta tahap Layanan Jasa dan konsultasi. 
Pengenalan Program, pada tahap ini tim pengabdian kepada masyarakat memperkenalkan rencana kegiatan pengabdian pada kelompok HIMAE, menjelaskan detail kegiatan yang akan dilakukan yang telah disepakati bersama. Pada tahap ini dibuat kesepakatan pengaturan waktu dan jadwal pelaksanaan penyampaian materi (penyuluhan) dan demontrasi pelaksanaan tekhnik pemanfaatan trichokompos pada budidaya sayuran. Hal ini dilakukan agar seluruh anggota kelompok HIMAE yang menjadi mitra dapat berpartisipasi dalam seluruh program yang direncanakan, menjamin pemerataan dan penyebaran ilmu pengetahuan dan ketrampilan pada mitra.

Program Demontrasi dan Pembinaan, kegiatan ini adalah kegiatan inti dari kegiatan yang dilaksanakan oleh tim pengabdian karena pada kegiatan ini nantinya kelompok HIMAE akan dapat mempraktekkan dan melihat langsung semua kegiatan yang akan diterapkan pada pemanfaatan trichokompos pada budidaya sayuran untuk menghasilkan sayuran organik yang akan mereka lakukan nantinya. Kegiatan demontrasi dan pembinaan ini dibagi atas:

1. Penyuluhan tentang manfaat dan cara penggunaan trichokompos pada budidaya sayuran organik.

2. Demontrasi tentang aplilkasi trichokompos pada budidaya sayuran organik.

3. Demplot pemanfatan trichokompos pada budidaya sayuran oranik.

4. Demontrasi tentang pengemasan sayuran organik sehingga mempunyai nilai jual yang tinggi sebagai salah satu usaha ekonomi (Wirausaha) mitra.

\section{HASIL DAN PEMBAHASAN}

Program pengabdian kepada masyarakat yang dilakukan bertujuan untuk memberi solusi pemanfatan pupuk organik sebagai pengganti pupuk kimia yang biasa digunakan. Pemanfaatan trichokompos ini merupakan kelanjutan dari PPM yang pernah dilaksanakan tahun lalu. Mitra dalam hal ini HIMAE mengaplilkasikan pupuk trichokompos pada budidaya sayuran yang menghasilkan sayuran organik bebas pestisida.

Pembinaan diarahkan pada ketrampilan kelompok sasaran dalam menghasilkan sayuran organik dengan memanfaatkan trichokompos dan kemasan produk agar bisa dipasarkan sebagai salah satu kegitan entrepreneurship bagi HIMAE. Pemantauan dan pembinaan kegiatan ini dilakukan secara berkala setiap bulan setelah kegiatan penyuluhan dan kegiatan lapangan.

\section{Diskusi dan Pertemuan Tim}
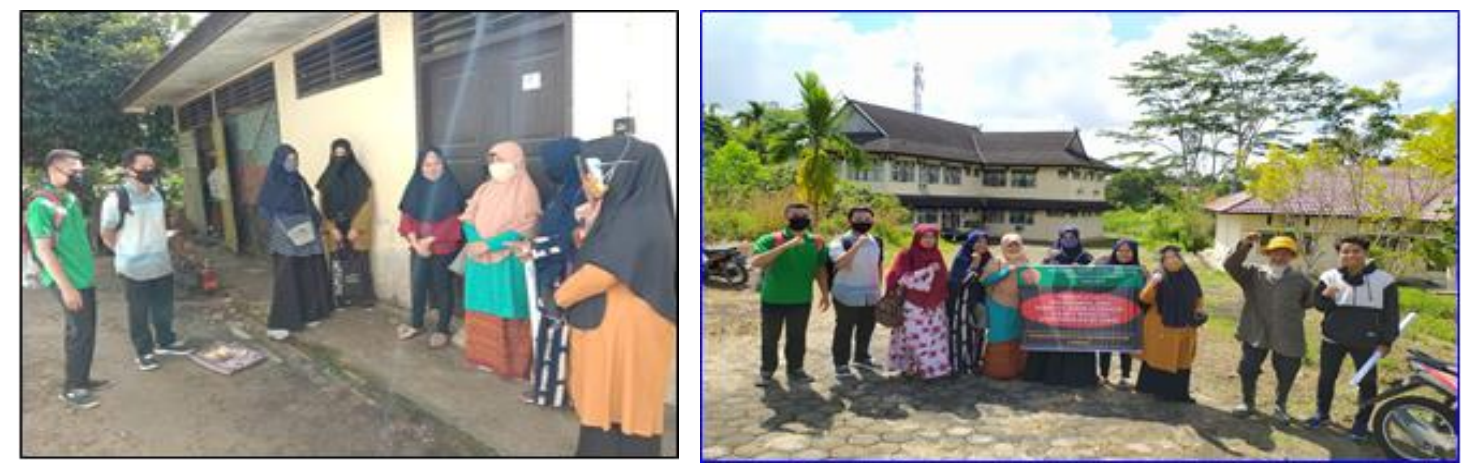

Setelah adanya diskusi antara mitra dan tim tentang penerapan pertanian organik di lapangan, mitra mulai mencoba membudidayakan sayuran dengan memanfaatkan trichokompos tanpa menggunakan bahan kimia lainnya. Diharapkan dari kegiatan budidaya sayuran organik ini akan dapat menjadi kegiatan entrepreneurship bagi HIMAE. Kegiatan ini akan dapat memberi manfaat bagi kesehatan karena sayuran yang dihasilkan bebas dari bahan kimia dan 
lingkunganpun menjadi bersih karena sampah organik yang dihasilkan telah dimanfaatkan untuk pembuatan trichokompos yang digunakan untuk pengganti pupuk kimia.

Dalam pelaksanaan dilapangan agar sayuran yang dihasilkan bisa dipanen setiap waktu maka mitra mencoba membuat petak petakan dilahan yang ditanam pada waktu yang berbeda dengan harapan dapat panen setiap waktu. Sementara ini sayuran yang dibudidaya adalah kangkung, bayam dan caisin. Saat ini sedang mereka tanam kacang panjang, buncis dan sayuran sebelumnya. Selain itu dipolibag mereka juga melakukan penanamna saladri dan cabe setan yang akan dipasarkan dalam bentuk bibit di polybag.

\section{Macam- macam Sayuran yang di Budidayakan}

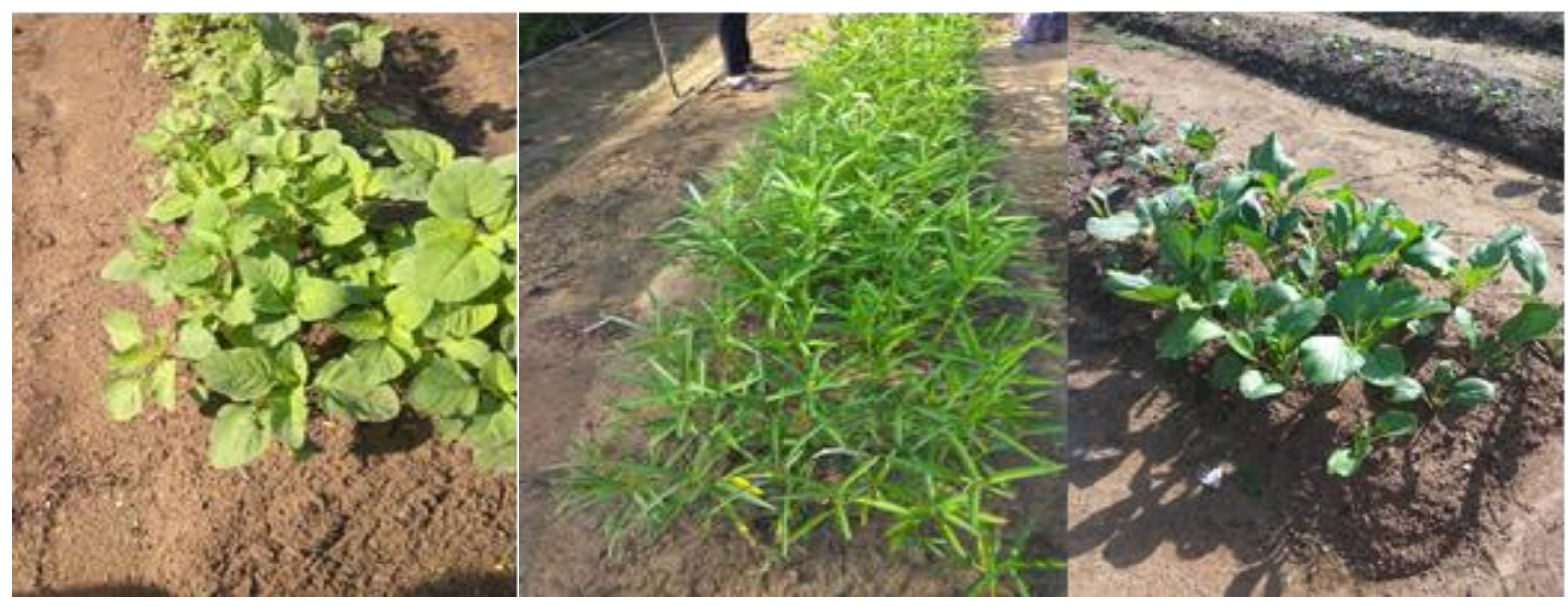

Sayuran ini akan dipanen pada waktu yang berbeda, sehingga sayuran organik yang dihasilkan dapat memenuhi kebutuhan masyarakat sekittarnya setiap waktu. HIMAE sebagai mitra juga akan melaksanakan pengemasan terhadap sayuran yang dihasilkan untuk dipasarkan. Sementara waktu pemasaran hanya dilakukan secara on line mengingat kodisi covid 19 yang sedang mewabah saat ini. Sayuran organik ini dikemas sedemikian rupa sehingga mempunyai tampilan yang dapat meningkatkan harga jual. Bagi kelompok HIMAE (mitra) sayuran organik dan trichokompos yang dihasilkan dapat menjadi kegiatan entrepreneurship sebagai kegiatan ekonomi di organisasi.

\section{Panen dan Pengemasan Sayuran Organik}

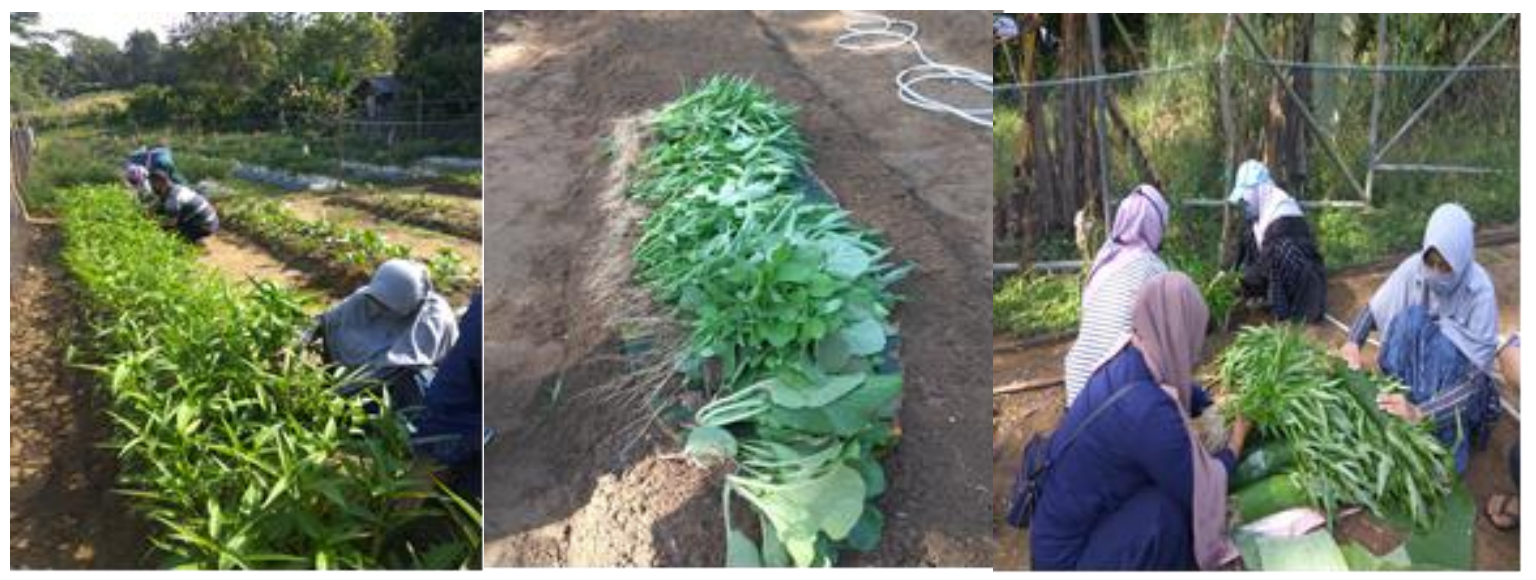




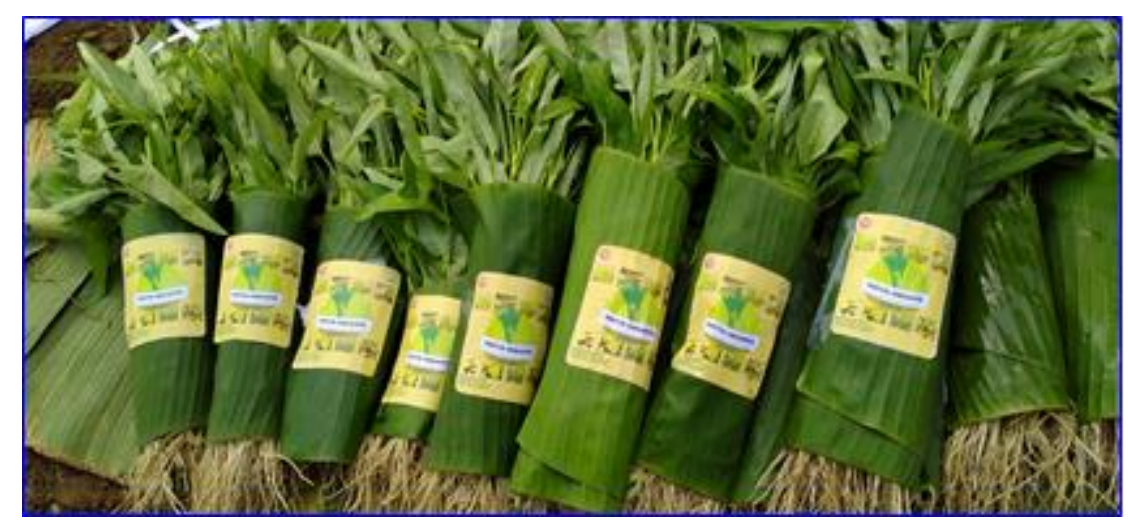

Penyuluhan, praktek dan demplot budidaya sayuran organic dengan memanfaatkan trichokompos yang berbahan baku sampah organic kampus ini telah menambah wawasan dan partisipasi anggota kelompok mitra dalam hal ini mahasiswa agroekoteknologi yang terhimpun dalam HIMAE untuk dapat menghasilkan sayuran organic sebagai upaya menciptakan kegiatan entrepreneurship dalam organisasi.

\section{Promosi Produk}
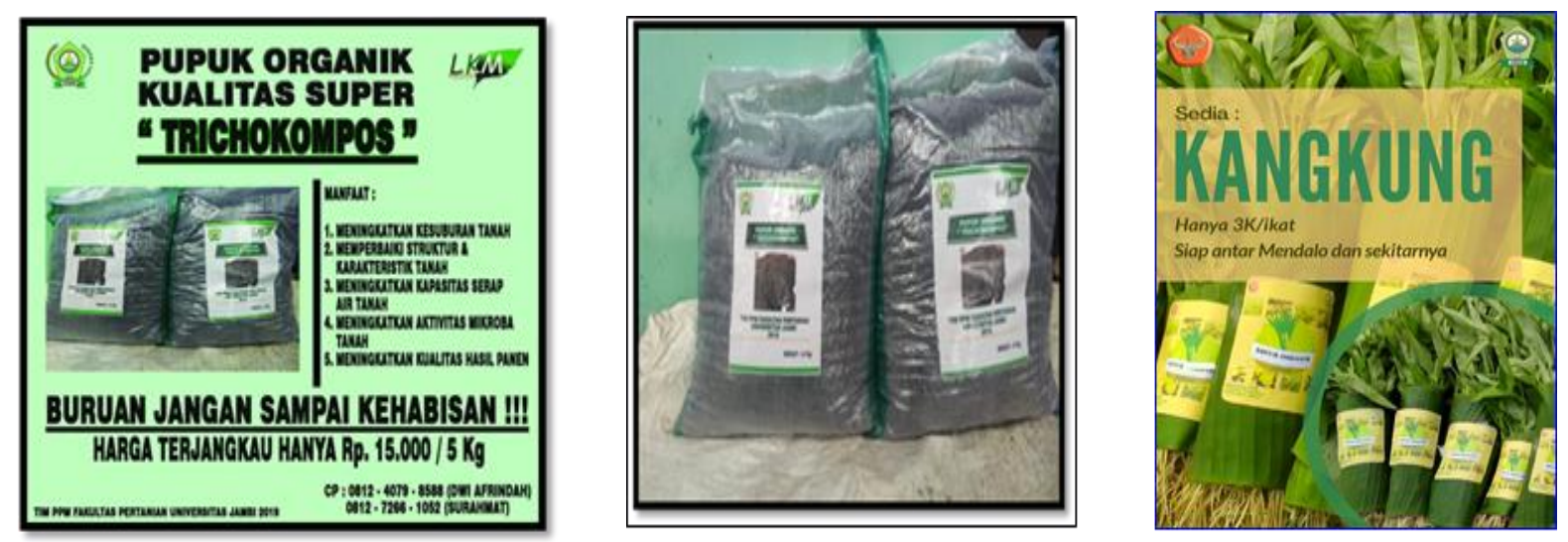

Evaluasi dirancang untuk mengetahui pencapaian dari setiap tahapan kegiatan yang dilaksanakan. Berdasarkan evaluasi ini dapat diketahui faktor-faktor yang menentukan keberhasilan kegiatan pengabdian. Rancangan evaluasi terdiri atas penilaian motivasi khalayak sasaran, kemampuan dan ketrampilan anggota kelompok dan keberlangsungan kegiatan. Evaluasi tahap pertama dilakukan pada kegiatan penyuluhan dan kegiatan lapangan, sedangkan pada tahap kedua dilakukan terhadap keberlangsungan penerapan teknologi yang diintroduksi.

Indikator yang digunakan untuk penilaian pencapaian tujuan penerapan ini adalah perubahan sikap kelompok sasaran selama mengikuti kegiatan. Tolok ukur yang digunakan untuk menilai keberhasilan ini adalah mitra mampu melakukan pertanian sayuran organik dengan memanfaatkan trichokompos berbahan baku sampah organik kampus. Kegiatan ini dapat dijadikan sebagai kegiatan entrepreneurship bagi HIMAE. 


\section{Kesimpulan}

Dari kegiatan yang dilakukan diperoleh :

1. Memanfaatkan sampah organik kampus sebagai bahan baku dari trichokompos yang akan di pakai pada budidaya sayuran organic.

2. Dapat dijadikan sebagai kegiatan entrepreneurship bagi kelompok mitra dalam hal ini adalah HIMAE

3. Mitra dapat menghasilkan sayuan organik dengan kemasan organic pula.

\section{Saran}

Untuk menambah kegiatan entrepreneurship untuk HIMAE sebaiknya kegiatan budidaya sayuran organic dan trichokompos ini pemasarannya tidak hanya secara online saja. Jenis sayurannya harus lebih bervariasi.

\section{UCAPAN TERIMA KASIH}

Terima kasih kepada Rektor Universitas Jambi, Ketua Lembaga Penelitian dan Pengabdian kepada Masyarakat, Dekan Fakultas Pertanian Universitas Jambi, yang telah memberikan bantuan dana dan Kelompok HIMAE Faperta UNJA yang menyediakan tempat sehingga pengabdian ini dapat dilaksanakan.

\section{DAFTAR PUSTAKA}

Arofi, F. dan S. Wahyudi. 2017. Budidaya sayuran organik di pekarangan. J.Perbal. 5(3): 1-9 Balai Pengkajian Teknologi Pertanian Jambi. 2009. Pemanfaatan Trichokompos pada Tanaman Sayuran. Balai Pengkajian Teknologi Pertanian Jambi, Jambi Mayrowani, H. 2012. Pengembangan Pertanian Organik Di Indonesia. Forum Penelitian Agro Ekonomi 30 (2): 91 - 108.

Sutanto, R. 2002. Penerapan Pertanian Organik. Yogyakarta: Kanisius

Yuliawati, T. 2015. Bertanam Sayuran Organik di Halaman Rumah. PT. Agromedia Pustaka, Jakarta. 